\title{
RESENHA DA OBRA CINEMATOGRÁFICA TARJA BRANCA: A REVOLUÇÃO QUE FALTAVA
}

\author{
FILM REVIEWTARJA BRANCA: A REVOLUÇÃO QUE FALTAVA
RESEÑA DE LA OBRA CINEMATOGRÁFICA TARJA BRANCA: A REVOLUÇÃO QUE FALTAVA
Kleber Tüxen Carneiro*, Maurício Bronzatto**, Eliasaf Rodrigues de Assis**, Alcides José Scaglia***

\section{Palavras-chave: Jogos e brinquedos. Criança.}

Narrativas pessoais.
Resumo: O presente texto dedica-se a refletir sobre o conteúdo lúdico do documentário Tarja Branca: a revolução que faltava, produção cujo objetivo central é compreender as dimensões e representações do que foi, e ainda é, para alguns dos entrevistados, 0 ato criador de brincar. Com delicadeza e profundidade, as narrativas, ao discutirem o que a essência lúdica (jogo) representou para a infância dos entrevistados, convergem para a construção da imagem do ser brincante (espírito lúdico). 0 documentário aborda, ainda, como a infância contemporânea se relaciona com as mesmas questões.

Abstract: The present text reflects upon the playful content of documentary film "Tarja Keywords:

Play and playthings. Children.

Personal narratives.

Palabras clave: Juego y juguetes. Niño.

Narrativas personales. branca: a revolução que faltava", whose main objective is to understand the dimensions and representations of what was - and still is, to some respondents - the creative act of playing. Gentle and deep, narratives discuss what the playful essence (play) represented for respondents' childhoods and converge to build the image of a playing being (playing spirit). The documentary also discusses how contemporary childhood relates to those issues.

Resumen: Este texto está dedicado a reflexionar sobre el contenido lúdico del documental "Tarja branca: a revolução que faltava", producción cuyo objetivo principal es comprender las dimensiones y representaciones de lo que fue, y aún es, para algunos de los entrevistados, el acto creativo del jugar. Con delicadeza y profundidad, los relatos recogidos, al discutir lo que representó la esencia lúdica (juegos) para la infancia de los entrevistados, convergen hacia la construcción de la imagen del ser juguetón (lúdico). El documental también aborda cómo se relaciona la infancia contemporánea con las mismas cuestiones.
* Universidade do Estado de Mato Grosso. Cáceres, MT, Brasil. E-mail: kleber2910@gmail.com

** Uninove. São Roque, SP, Brasil. E-mail: maub1970@ig.com.br ; eliasafassis@gmail.com

*** Unicamp. Limeira, SP, Brasil. E-mail: alcides.scaglia@gmail.com

Recebido em: 13-08-2015 Aprovado em: 19-12-2015 (c) (1) (2) Licence 
Gilles Deleuze (1990), em suas alusões quanto ao cinema e o fenômeno da imagética, adverte que o fundamental em uma experiência de desfrute de uma obra cinematográfica é dela extrair um pensamento. $O$ filósofo sugere que não se analise um filme, por exemplo, a partir de sua exterioridade. Antes, o espectador deve criar cartografias capazes de validar o cinema como um sistema de pensamento.

Nesse sentido, o presente texto empreende seu esforço no intento de cotejar e mapear as várias cartografias contidas no conteúdo do documentário brasileiro Tarja Branca: a revolução que faltava - uma mensagem sobre a urgência do resgate do espírito lúdico1 e criativo que existe no ser humano, por intermédio das diferentes formas e possibilidades de concretização do jogo (CARNEIRO, 2015).

A proposta do documentário é refletir, a partir do depoimento de várias personalidades - artistas, educadores e dançarinos, entre outros -, sobre a importância do ato criador e transcendente presente nas manifestações do brincar. De saída, destaca-se a assertividade contida no título: tacitamente, à maneira de um trocadilho, põe em destaque o efeito terapêutico e catártico do jogo. "Tarja branca" faz um contraponto aos medicamentos com classificação "tarja preta", utilizados no tratamento das doenças psicossomáticas. $\mathrm{O}$ uso de tais medicamentos e similares é uma marca expressiva dos dias atuais e não está circunscrito apenas ao público adulto. Atinge também o infantil. 0 documentário explicita, ainda, o caráter subversivo, transformador e transcendente promovido pelo jogo, um fenômeno já sinalizado por alguns estudiosos (FREIRE, 2001, 2002; SCAGLIA, 2003).

O enredo da obra convida e provoca o telespectador a alforriar o seu "ser brincante" e a dar largas a um estado de ludicidade perene, intrínseco à existência humana, semelhantemente ao que propõe Huizinga (1999) quando afirma que, muito mais do que racionais, somos lúdicos - homo ludens. 0 despertar e a construção cultural do jogo constituem um fundamento de nossa própria condição existencial. Foi o que evidenciou $\mathrm{C}$. G. Jung em seu relato pessoal de elaboração enquanto brincava, estabelecendo uma ponte com a criança que nele existia:

Abandonei-me assim, conscientemente, ao impulso do inconsciente. A primeira
coisa que se produziu foi o aparecimento de uma lembrança da minha infância,
talvez dos meus dez ou doze anos. Nesta época eu me entregava apaixonadamente
a brinquedos de construção [...] "Ah, ah, disse a mim mesmo, aqui há vida! O
garoto anda por perto e possui uma vida criativa que me falta. Mas como chegar
a ela?" Parecia-me impossível que o homem adulto transpusesse a distância
entre o presente e meu décimo primeiro ano de vida. Se eu quisesse, entretanto,
restabelecer o contato com essa época de minha vida, só me restava voltar a ela
acolhendo outra vez a criança que então se entregava aos brinquedos. [...] Todos
os dias depois do almoço, se o tempo permitia, eu me entregava ao brinquedo de
construção. (JUNG, 1963, p.154 e 155. O grifo é nosso.)

Em alguma medida, "podemos considerar que a disposição humana para o jogo decorre de uma compreensão do substrato ontológico do lúdico presente na própria ordem cósmica" (BITTENCOURT, 2014, p. 16). As narrativas contidas no documentário suscitam uma condição interior, em que o espírito lúdico promove uma harmonia imediata com a potência criadora em todo o universo (CARNEIRO, 2015). No mesmo sentido, Schiller (1990) considera que o impulso lúdico atua no sentido de suprimir o tempo dentro do tempo, conciliando o devir com o seu absoluto, a mudança com a identidade. 
Tarja branca recorre a diferentes narrativas, cujo teor é um convite ao despertamento do Ser brincante ${ }^{1}$, uma voz que apregoa a libertação do espírito lúdico, muito característico e marcante quando se trata do universo infantil. Contudo, absolutamente esquecido e/ou adormecido quando diz respeito ao mundo dos adultos.

O documentário é uma crítica incisiva à vida estressante, demasiadamente séria; uma denúncia contundente contra as estafantes jornadas de trabalho, com sua asfixiante sensação de falta de tempo; uma expressão de profundo descontentamento com a pouca liberdade do ambiente das ocupações profissionais, em que os afazeres se multiplicam e impossibilitam 0 espaço para o surgimento da inspiração criadora tão presente nos domínios do jogo (lúdico).

Ao encetar uma narrativa delicada, tecida com o fio das experiências de diferentes entrevistados, o diretor Cacau Rhoden executa um movimento que desconstrói a desvalorização e a depreciação do ato criador de brincar. Os depoimentos alvitram um rompimento com a lógica tecnocrata, instrumental e produtivista do mundo globalizado, convidando o telespectador a ressignificar seu entendimento lúdico.

Percorrendo diferentes cenários e contextos deste imenso Brasil, o registro vai garimpando as riquezas dos conteúdos lúdicos. Discute, a todo momento, o que representaram o jogo e a brincadeira para a infância dos entrevistados e como o homem contemporâneo se relaciona com esse "espírito lúdico" tão essencial.

A miscigenação racial e cultural também se vê retratada nas memórias dos brincantes. Essa característica "festiva", há muito percebida, entre outros, pelo antropólogo Darcy Ribeiro (1922-1997), é um aspecto fundante do povo brasileiro. Trata-se de uma peculiaridade de nossa cultura e arte popular, que é permeada por traços brincantes. As manifestações de arte estão conectadas à mesma raiz do impulso lúdico. Como bem observou uma das entrevistadas do documentário, "a grande riqueza da cultura popular reside na possibilidade de viver uma segunda infância" (TARJA BRANCA: a revolução que faltava, 2014, trecho 53:15 min.).

A beleza e a riqueza da obra podem ser facilmente percebidas com base no excerto a seguir: "O que falta muito neste mundo é um pouco de brincadeira, entendeu? Em tudo! Quando você perde essa capacidade de brincar, eu acho que você perde uma conexão com sua essência!" (TARJA BRANCA: a revolução que faltava, 2014, trecho 4:30 min.). Ou, ainda, neste outro: "Para mim a brincadeira está mais subterrânea que o nível da cultura, ela mora num rio assim, abaixo da terra, e é ali que todo mundo vai beber naquela fonte" (TARJA BRANCA: a revolução que faltava, 2014, trecho 16:30 min.).

Há um esforço, em todo o documentário, para revelar o cerne potencializador da experiência lúdica, como fica perceptível na fala de outra entrevistada:

É um ato que rompe o tempo e o espaço e inaugura um outro tempo e espaço em uma conexão de vínculo, entre o ser e o mundo, não é? Porque a criança não vive para brincar, brincar é viver, ela totalmente inteira, respondendo a sua própria vida, a vida está se exprimindo dentro dela ali! (TARJA BRANCA: a revolução que faltava, 2014, trecho 12:51 min.).

[...] É uma linguagem do corpo com a psique, ela está ali por inteiro, essa lembrança do brincar, é a lembrança da unidade, e essa unidade, eu acho que é o que o homem procura a vida inteira (TARJA BRANCA: a revolução que faltava, 2014, trecho 13:42).

10 termo brincante é utilizado nas regiões Norte e Nordeste do Brasil pelos artistas populares, nas suas diversas expressões: dança, música, artes plásticas, poesia, brinquedos, brincadeiras etc. Os artistas populares não se denominam músicos ou atores, e sim "brincantes". Eles brincam com a arte de se expressar. 
Outro ponto abordado que merece destaque é o enaltecimento dos conteúdos formativos advindos do jogo, como se depreende da narrativa de um dos entrevistados: "Bola de gude, pião e papagaio e hoje eu vejo todo um... uma ciência, uma sabedoria, que tem aí. Tem a época de empinar papagaio, de brincar de bola de gude e pião, tem a ver com 0 vento, com a natureza. São esses ciclos maiores que a gente vive através dessas brincadeiras" (TARJA BRANCA: a revolução que faltava, 2014, trecho 5:30 min.).

Na mesma direção, uma participante destaca a valorização dos elementos constituintes do/no brincar:

Acho que a cultura humana está na cultura da criança de uma forma elementar! Não tenho dúvida nenhuma, entendeu? Todas as artes, a música, o movimento, a dança, o teatro, a literatura... é outra coisa tão preciosa de você examinar: as formas literárias nos brinquedos de criança! (TARJA BRANCA: a revolução que faltava, 2014, trecho 16:51 $\mathrm{min}$.).

A dimensão libertadora presente na ambiência lúdica também é observada por um entrevistado para quem "o essencial do brincar é a liberdade de tempo, liberdade de espaço e liberdade de criação!" (TARJA BRANCA: a revolução que faltava, 2014, trecho 14:15 min.).

Entretanto, um dos grandes destaques contidos no filme diz respeito ao declínio de algumas dessas manifestações. A substância desse substrato lúdico está se desfazendo na contemporaneidade. Ela é colocada em perigo pelas bruscas mudanças do tempo presente. O risco a essa dimensão tão peculiar da composição humana é percebido por uma das entrevistadas: "É assustador quando a gente põe numa roda um monte de crianças e fala: 'O que você mais gosta de fazer é brincar ou ir ao shopping?' E nove, das dez crianças, dizem ir ao shopping! Quer dizer, é claro que entrou como uma substituição" (TARJA BRANCA: a revolução que faltava, 2014, trecho 16:51 min.).

Destacam-se, ainda, as ameaças que circundam o modus operandi do brincar atualmente. Sobretudo a interferência da indústria do entretenimento e a comercialização em escala industrial do brinquedo, como notou David Reeks, um dos entrevistados:

Quando uma criança pensa 'eu quero fazer um carrinho' (...) quando ele pensa, tem esse estalo, 'eu quero e consigo fazer' (este) é o início do ciclo do brincar. $\mathrm{Na}$ sociedade onde vivemos, esse ciclo do brincar a criança só pega no final. Porque o desejo está dado pela indústria, a criação está dada pelos inventores. Os engenheiros fizeram o brinquedo, e a criança só pega o brinquedo pronto e brinca com ele, mas em seguida já quer outro. Ela não tem a coisa por completo. (TARJA BRANCA: a revolução que faltava, 2014, trecho 14:20 min.).

Esse furto da essência lúdica humana se apresenta de muitas formas e sob a égide de diferentes discursos pautados por distintos modelos: 0 da eficiência tecnicista, aquele do aligeiramento do tempo ou o outro da utilidade e preparação para o futuro. Como bem descreveu um dos entrevistados: "As crianças com 4, 5, 6 etc. já aprendem balé, inglês, sapateado. É muita coisa que se enfia na cabeça! $E$ vai crescendo um adulto muito preocupado..." (TARJA BRANCA: a revolução que faltava, 2014, trecho 22:50 min.).

Outro participante parece compartilhar da mesma preocupação desse furto utilitarista da infância: gosto muito de deixá-los sem fazer nada, eles ficam meio aflitos às vezes. Assim... 
meio "assim"... e dizem: "Eu não tenho nada o que fazer". E eu digo: "Olha para o teto, pensa em alguma coisa". Eu acho muito importante termos um tempo para não fazer nada. (TARJA BRANCA: a revolução que faltava, 2014, trecho 23:10 $\min$.$) .$

Essa engrenagem tecnocrática, tal como um rolo compressor, acaba por "achatar" a infância. $E$ também alcança as searas educacionais, onde se faz fortemente presente, mesmo em alguns dos discursos da pedagogia contemporânea. Parece existir um muro simbólico entre a infância (isto é, o "ser criança") e a escola, sobretudo quando o assunto é a atividade lúdica e o jogo em suas diferentes manifestações. É o que observa uma das entrevistadas: "Na área da educação, quando você fala sobre o brincar, todo mundo diz: 'Ah é'... Mas não se leva tão a sério, sabe? Ainda é difícil essa compreensão... todo mundo acha que educação é uma outra coisa, que é apreender isso, aprender aquilo [...]" (TARJA BRANCA: a revolução que faltava, 2014, trecho 19:28 min.).

O documentário reforça os indícios da presença de uma desconfiança quanto ao brincar. Isso fica evidente no depoimento enfático de uma entrevistada:

\begin{abstract}
Tem que chegar alguém da universidade de Harvard, que fez uma pesquisa durante muito tempo, neurocientista junto com antropólogos, com o sociólogo, com 0 psicólogo e pedagogo; que percebeu no cérebro da criança, que ele se desenvolve, que as sinapses ocorrem assim, assado... e então, por isso é fundamental o brincar nesta faixa etária. Então, gente, não vamos colocar computador na criança de dois anos, é melhor deixar ela brincar! (TARJA BRANCA: a. A revolução que faltava, 2014, trecho 22:40 min.).
\end{abstract}

E, por fim, esta produção clama por um resgate do substrato lúdico, ou seja, pelo esteio da essência humana. Ela convida o espectador a redescobrir o corpo como ofício da alegria, do brincar. E estabelece que este estado humano de convivência com a brincadeira é tarja branca, ou uma medicina psicolúdica. Sugere, ainda, como no rememorar de uma fotografia, que conectar-se às reminiscências de outrora, da infância esquecida, é um ato profilático. Como conclui uma das entrevistadas:

Este milagre do ser humano ainda novo acontece e continua acontecendo, ele está inteiro, ele vem outra vez, com todas as promessas. Então eu acho que a fórmula é: olhar menino, aprender menino, reaprender menino, e pronto, é só isso. E é muito simples, só senta em seu corpo, todo mundo tem o seu corpo e tem uma criança dentro. Deixe ela brincar, não vai acontecer talvez no primeiro dia, mas o reconhecimento já é o fato de habitar o território sagrado da infância. (TARJA BRANCA: a revolução que faltava, 2014, trecho 1:14:24 min.).

O documentário é, portanto, uma "ode ao ser brincante".

\title{
REFERÊNCIAS
}

BITTENCOURT, Renato Nunes. O lúdico para questionar. São Paulo: Filosofia Ciência \& Vida, v.7, n. 82, p. 15-23. 2014.

CARNEIRO, Kleber Tüxen. 0 jogo na educação física escolar: uma análise sobre as concepções atuais dos professores. 2009 168f. Dissertação (Mestrado em Educação Escolar) Faculdade de Ciências e Letras, Universidade Estadual Paulista, Araraquara, 2009.

CARNEIRO, Kleber Tüxen. 0 Jogo na Educação Física. São Paulo: Phorte, 2012. 
CARNEIRO, Kleber Tüxen. Por uma memória do jogo: a presença do jogo na infância das décadas de 20 e 30. 2015. 273f. Tese (Doutorado em Educação Escolar) Faculdade de Ciências e Letras, Universidade Estadual Paulista, Araraquara, 2015.

DELEUZE, Gilles. A imagem-tempo. São Paulo: Brasiliense, 1990.

FREIRE, João Batista. Investigações preliminares sobre o jogo. Campinas: FEF- UNICAMP (Tese de livre docência), 2001.

FREIRE, João Batista. Jogo: entre o riso e o choro. Campinas: Autores Associados, 2002.

HUIZINGA, Johan. Homo Ludens: o jogo como elemento da cultura. 4. ed. São Paulo: Perspectiva, 1999.

JUNG, Carl Gustav. Memórias, Sonhos e Reflexões. Rio de Janeiro: Nova Fronteira, 1963.

SCAGLIA, Alcides José. 0 futebol e os jogos/brincadeiras de bola com os pés: todos

semelhantes, todos diferentes. 2003. 164f. Tese (Doutorado em Pedagogia do Movimento) Faculdade de Educação Física, Universidade de Campinas, Campinas, 2003.

SCHILLER, Friedrich. A educação estética do homem numa séria de cartas e outros textos. São Paulo: lluminuras, 1990.

TARJA BRANCA: a revolução que faltava. Direção de Cacau Rhoden. Produção Executiva de Estela Renner, Luana Lobo e Marcos Nisti. Roteiro de Cacau Rhoden; Estela Renner; Marcos Nisti. Intérpretes: Domingos Montagner; Wandi Doratiotto; Antônio Nóbrega; José Simão. Música: André Caccia Bava. São Paulo: Maria Farinha Filmes, 2014. 1 DVD (80 min.), son., color. Documentário. 